\title{
Multiperiod Coordination Models of Coal-Electricity Supply Chain with Double Price Regulations
}

\author{
Hongjun Peng, ${ }^{1}$ Meihua Zhou, ${ }^{2}$ and Fudong Wang ${ }^{2}$ \\ ${ }^{1}$ College of Economics and Management, Nanjing Forestry University, Nanjing 210037, China \\ ${ }^{2}$ School of Management, China University of Mining and Technology, Xuzhou 221116, China \\ Correspondence should be addressed to Meihua Zhou; mhzhou63@126.com
}

Received 17 April 2015; Revised 22 June 2015; Accepted 29 June 2015

Academic Editor: Chris Goodrich

Copyright (c) 2015 Hongjun Peng et al. This is an open access article distributed under the Creative Commons Attribution License, which permits unrestricted use, distribution, and reproduction in any medium, provided the original work is properly cited.

\begin{abstract}
Using game models, we study multiperiod coordination contract and model of coal-electricity supply chain under the condition of double price regulations to alleviate the price conflicts of coal and electricity enterprises. The study reveals that, in boom seasons of coal demand, the multiperiod coordination mechanism may not only reduce the price of thermal coal but also increase the fulfillment rate of thermal coal. Meanwhile, the ordering quantity of thermal coal is increased and the shortage probability of electricity supply is decreased. Thereby, the conflicts between coal and electricity are also alleviated effectively.
\end{abstract}

\section{Introduction}

There are double price regulations in coal-electricity supply chain in China [1]. Firstly, the government adopts the transverse dual-track price system for coal; that is, the price of the thermal coal is regulated and the market-oriented price system for other coal is carried out. The government tried to let go the price control of thermal coal since 2002. However, the price of the thermal coal is still regulated by government. Facing the ever-increasing price of the thermal coal, National Development and Reform Commission has more than once exerted the temporary intervention on the price of thermal coal since 2008. Secondly, there exists a longitudinal dualtrack price system between coal and electricity. Under the circumstance of lifting the control of the price of thermal coal step by step, the price of the electricity is but strictly regulated by the government.

In recent years, the tension of coal-electricity relationship in China is highlighted. The price conflicts of supply and demand of the thermal coal for a certain region and a certain period appear from time to time. Especially at the time of hot summer, cold winter, and unexpected natural disasters, the problem stands out as extremely serious. This often leads to periodic power shortages. Under conditions of double price regulations, it is necessary to study how to coordinate the coal-electricity supply chain to ease the conflicts between coal and electricity.

Although price regulation in coal-electricity supply chain has been noticed by many authors, most of them only pay attention to single price regulation. Some authors measured the impact of regulatory measures which affected the wholesale market and the possibility that price regulation increases a monopolist's cost efficiency, respectively [2-6]. Some other authors studied the incentives of regulated firms' investment and strategic behavior [7-14]. Few literatures studied the coordination mechanism under the condition of price regulation, except that $[15,16]$ studied the revenue (profit) sharing coordination under price cap regulation.

Many scholars studied the decision-making problem of the supply chain with season pattern demand. Most of the authors studied the optimal production, inventory, or order lot size with fluctuating demand [17-27]. Some authors studied the optimal replenishment policy for product with season pattern demand [28-30]. Hsu and Li [31] focused on supply chain network design problems by considering economies of scale and demand fluctuations.

Some other scholars studied the coordination mechanism of the supply chain with season pattern demand. Chang 
and Chou [32] considered a single product coordination system using a periodic review policy. Dye and Ouyang [33] established a deterministic economic order quantity model for a retailer to determine its optimal selling price, replenishment number, and replenishment schedule with fluctuating demand under two levels of trade credit policy. Cho and Lee [34] used three levels of information sharing to coordinate the supply chain in order to evaluate the value of information sharing in a two-echelon seasonal supply chain. $\mathrm{Wu}$ and Zhang [35] presented an investigation on simulation of interaction between customers and suppliers in a three-tier supply chain system. In the simulation, customers respond to the price discount offer made by the supplier and the supplier adjusts the price according to stock held. Chen and $\mathrm{Xu}$ [36] introduced an improved operating system whose impact to both bodies of a supply chain is examined under the condition of information symmetry.

Some scholars studied the multiperiod decision-making and coordination problem of the supply chain with season pattern demand. Chen and Xiao [37] developed a two-period game model of a supply chain including one manufacturer and one retailer to investigate the optimal decisions of the players. Liu et al. [38] examined the use of price-commitment policies in dynamic contracting in multiple-period, finitetime horizons. Aviv and Federgruen [39] addressed multiitem inventory systems with random and seasonally fluctuating demands. Some authors consider demand models in the dynamic pricing setting, where past prices affect the current demand via reference price formation mechanisms [40-42]. Besanko and Winston [43] consider a markdown pricing mechanism of a monopolist facing a fixed number of customers during a planning horizon. Being most closely related to [44, 45], Ahn et al. [46] modeled a joint manufacturing/pricing decision problem, accounting for that portion of demand realized in each period that is induced by the interaction of pricing decisions in the current period and in previous periods. However, the price regulation was mostly not taken into consideration in the above literatures.

To our knowledge, only [9] established a multiperiod game model under three scenarios: no regulation, a dynamic setting where the price cap adjustment mechanism is not adopted by the players, and a dynamic setting where it is adopted by the players.

According to the above literature review, few literatures probe into the in-depth study of the impacts of the price regulation and fewer literatures studied the coordination mechanisms under the condition of price regulation. The price regulation is mostly not taken into consideration in the literatures that studied the decision-making and coordination problem of the supply chain with season pattern demand. To our knowledge, only Peng et al. [47] studied the decisionmaking and coordination problem under the conditions of double price regulations. The paper studied the peak shaving reserve mechanism of coal-electricity supply chain under conditions of double price regulations. But the construction of peak shaving reserve warehouses of thermal coal is always beyond the enterprises' ability.

Under conditions of double price regulations, the transverse price double track caused by coal price regulation and

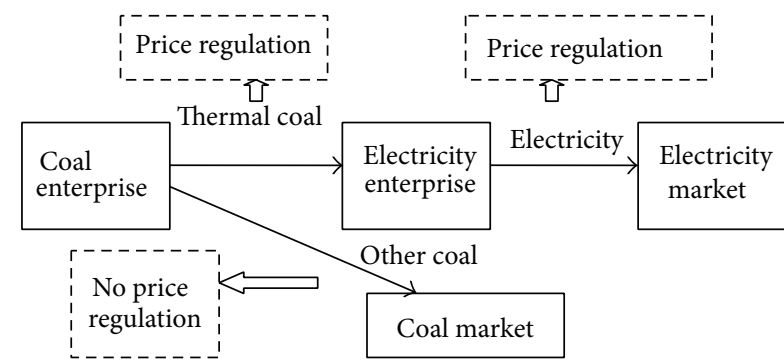

FIGURE 1: Coal-electricity supply chain with double price regulations.

the longitudinal price double track caused by electricity price regulation should be eased to solve the price conflict of coal and electricity. A coal-electricity supply chain including one coal enterprise and one electricity enterprise is taken as the object of study (see Figure 1), where the prices of the thermal coal and electricity are regulated and the demand of coal has the characteristics of seasonal fluctuations. Based on the study of the impact of double price regulations on the decisions of producing or supplying of coal and electricity [47], this paper studies the multiperiod coordination mechanism to coordinate the coal-electricity supply chain.

Compared with the literatures, the main contributions of the paper can be summarized as follows. Firstly, we analyze the impact of the double price regulations of the thermal coal and electricity. Secondly, we study multiperiod coordination mechanism and model of coal-electricity supply chain with the dynamic coordination variables of the price and the fulfillment rate. Thirdly, we prove theoretically that, in boom seasons of coal demand, the multiperiod coordination mechanism may not only reduce the price of thermal coal but also increase the fulfillment rate of thermal coal. Meanwhile, the ordering quantity of thermal coal is increased and the shortage probability of electricity supply is decreased. Thereby, the multiperiod coordination mechanism may ease the conflicts between coal and electricity.

\section{Major Assumptions and Notations}

2.1. Notations. The following notations are used throughout this paper.

Subscript or Superscript

$t$ : subscript, the period, where $t=1$ is the boom season, and $t=2$ is the slack season,

$s$ : subscript, coal enterprise,

$m$ : subscript, electricity enterprise,

$U$ : superscript, the decision without coordination,

DC: superscript, the decision with coordination.

\section{Parameters}

$P_{m}$ : the price of electricity,

$C_{m}$ : the generating cost, 
$\xi$ : the generating quantity per unit coal,

$R_{m}$ : the shortage cost of electricity supply,

$P_{s t}$ : the market price of coal,

$X$ : a random variable, with probability density function $f(\cdot)$,

$D_{m t} X$ : the demand of electricity,

$D_{o t}$ : the order quantity of other coal,

$Q_{s t}$ : the output capacity of coal,

$C_{s}$ : the production cost of coal,

$H_{s}$ : the inventory cost of coal.

\section{Decision Variables}

$q_{m t}$ : the order quantity of thermal coal, decided by electricity enterprises,

$\alpha$ : the rate of price inflation of the thermal coal in boom seasons, decided by coal enterprises,

$\lambda$ : the fulfillment rate of the thermal coal in boom seasons, decided by coal enterprises,

$\lambda_{0}$ : the basic ordering proportion of the thermal coal, decided by electricity enterprises,

$\beta$ : the dynamic coordinate parameter of the fulfillment rate, decided by electricity enterprises,

$\gamma$ : the dynamic coordinate parameter of the price, decided by electricity enterprise.

\subsection{Major Assumptions}

(1) Due to the price regulation of electricity, the electricity price is not changed during a boom season and a slack season of coal demand.

(2) Due to the price regulation of thermal coal, the rate of price inflation of the thermal coal in the boom season should not exceed $\alpha_{0}$; that is, $\alpha \leq \alpha_{0}$. Under the conditions of price regulation of thermal coal, the negotiated price of the thermal coal is far lower than the market price of other coal.

(3) Coal enterprise and electricity enterprise are both rational.

(4) The expected value of $X$ is 1 ; that is, the expected value of the demand of electricity is $D_{m t}$.

(5) The coal enterprises should assume the losses caused by the shortage of the thermal coal, which includes intangible cost such as credit loss and government punishment because of short supply. We assume that the shortage cost of thermal coal is an increasing marginal function of the shortage. Let the shortage cost be $R_{s}(1-\lambda)^{2} q_{m 1}$, and $R_{s}$ is the shortage cost coefficient.

\section{The Multiperiod Coordination Mechanism of Coal-Electricity Supply Chain}

3.1. The Design of Multiperiod Coordination Contract. The principle of the multiperiod coordination contract is as follows.

(1) In order to punish the coal enterprise for reducing coal supplies in the boom season of coal demand, the electricity enterprise reduces the ordering quantity of thermal coal in the slack season of coal demand. The reduced rate of the ordering quantity of thermal coal is $\beta(1-\lambda)$, while the remainder is purchased from other coal enterprises. Therefore, the electricity enterprise's ordering quantity of thermal coal from the coal enterprise in the slack season is $\left[\lambda_{0}-\beta(1-\lambda)\right] q_{m 2}$, where $\lambda_{0}$ is the basic ordering proportion of the thermal coal. We call $\beta$ the dynamic coordinate parameter of the fulfillment rate.

(2) In order to adjust the rate of price inflation of the thermal coal in the boom season, the electricity enterprise decides that the basic ordering proportion of the thermal coal is $\lambda_{0}=1-\gamma \alpha$ in the slack season of coal demand. We call $\gamma$ the dynamic coordinate parameter of the price.

Under the multiperiod coordination mechanism, the coal enterprise makes the decisions of $\lambda$ and $\alpha$, and the electricity enterprise makes the decisions of $q_{m 1}, q_{m 2}, \beta$, and $\gamma$.

3.2. Multiperiod Coordination Models of Coal-Electricity Supply Chain. The decision-making processes of coal-electricity supply chain under the situation of multiperiod coordination mechanism are as follows: (1) the electricity firm decides on $\beta$ and $\gamma$; (2) the coal firm decides on $\alpha$; (3) the electricity firm chooses $q_{m t} ;$ (4) the coal firm chooses $\lambda$.

According to the backward induction, we establish and solve multiperiod coordination models of coal-electricity supply chain.

\subsubsection{The Decision-Making of the Fulfillment Rate of Thermal} Coal in the Boom Season of Coal Demand by the Coal Enterprise. The coal enterprise makes the decisions of the fulfillment rate of thermal coal in boom seasons under the situation that $\beta, \gamma, \alpha, q_{m 1}$, and $q_{m 2}$ are known. Under the situation of multiperiod coordination mechanism, the total profit of the coal enterprise in the periods of one boom season and one slack season is

$$
\begin{aligned}
\pi_{s}^{\mathrm{DC}}= & (1+\alpha) P_{s 2} \lambda q_{m 1}+P_{s 1}\left(Q_{s 1}-\lambda q_{m 1}\right) \\
& +P_{s 2}\left\{\left[\lambda_{0}-\beta(1-\lambda)\right] q_{m 2}+D_{o 2}\right\} \\
& -R_{s}(1-\lambda)^{2} q_{m 1} \\
& -C_{s}\left\{Q_{s 1}+\left[\lambda_{0}-\beta(1-\lambda)\right] q_{m 2}+D_{o 2}\right\} .
\end{aligned}
$$

The first term in the profit function corresponds to the sales revenue of thermal coal in the boom season, the second term is the sales revenue of other coal in the boom season, the third term is the sales revenue of coal in the slack season, the fourth term is the shortage cost of thermal coal, and the fifth term is the production cost of coal. 
Proposition 1. Under the situation of multiperiod coordination mechanism and in the periods of one boom season and one slack season, the profit of the coal enterprise is a concave function of the fulfilment rate of thermal coal in the boom season. Under this situation, $\lambda^{D C}$ satisfies the following model:

$$
\lambda^{D C}=1-\frac{P_{s 1}-(1+\alpha) P_{s 2}}{2 R_{s}}+\frac{\left(P_{s 2}-C_{s}\right) \beta q_{m 2}}{2 R_{s} q_{m 1}} .
$$

We have the proof of Proposition 1 in the Appendices.

3.2.2. The Decision-Making of the Ordering Quantity of the Thermal Coal by the Electricity Enterprise. The electricity enterprise makes the decisions of the ordering quantity of the thermal coal under the situation that $\beta, \gamma$, and $\alpha$ are known. Under the situation of multiperiod coordination mechanism, the total expected profit of the electricity enterprise in the periods of one boom season and one slack season is

$$
\begin{aligned}
\pi_{m}^{\mathrm{DC}}= & \left(P_{m}-C_{m}\right) \min \left(D_{m 1} X, \xi \lambda q_{m 1}\right) \\
& -(1+\alpha) P_{s 2} \lambda q_{m 1}
\end{aligned}
$$

$$
\begin{aligned}
& -R_{m} \max \left(D_{m 1} X-\xi \lambda q_{m 1}, 0\right) \\
& +\left(P_{m}-C_{m}\right) \min \left(D_{m 2} X, \xi q_{m 2}\right)-P_{s 2} q_{m 2} \\
& -R_{m} \max \left(D_{m 2} X-\xi q_{m 2}, 0\right),
\end{aligned}
$$

where the first term is the difference of the sales revenue with the generating cost in the boom season, the second term is the purchase cost of thermal coal in the boom season, the third term is the shortage cost of power in the boom season, the fourth term is the difference of the sales revenue with the generating cost in the slack season, the fifth term is the purchase cost of thermal coal in the slack season, and the sixth term is the shortage cost of power in the slack season.

According to the assumption that the electricity enterprise is rational, the electricity enterprise makes decisions of the ordering quantity of thermal coal based on the decisionmaking of the fulfillment rate of thermal coal in the boom season of coal demand by the coal enterprise, that is, formula (2). The decision-making model is

$\max E \pi_{m}{ }^{\mathrm{DC}}$

$$
\begin{aligned}
& =\left(P_{m}-C_{m}\right)\left[\int_{0}^{\xi \lambda q_{m 1} / D_{m 1}} D_{m 1} x f(x) d x+\int_{\xi \lambda q_{m 1} / D_{m 1}}^{+\infty} \xi \lambda q_{m 1} f(x) d x\right]-(1+\alpha) P_{s 2} \lambda q_{m 1} \\
& \quad-R_{m} \int_{\xi \lambda q_{m 1} / D_{m 1}}^{+\infty}\left(D_{m 1} x-\xi \lambda q_{m 1}\right) f(x) d x+\left(P_{m}-C_{m}\right)\left[\int_{0}^{\xi q_{m 2} / D_{m 2}} D_{m 2} x f(x) d x+\int_{\xi q_{m 2} / D_{m 2}}^{+\infty} \xi q_{m 2} f(x) d x\right] \\
& \quad-P_{s 2} q_{m 2}-R_{m} \int_{\xi q_{m 2} / D_{m 2}}^{+\infty}\left(D_{m 2} x-\xi q_{m 2}\right) f(x) d x \\
& \text { s.t. } \quad \lambda^{\mathrm{DC}}=1-\frac{P_{s 1}-(1+\alpha) P_{s 2}}{2 R_{s}}+\frac{\left(P_{s 2}-C_{s}\right) \beta q_{m 2}}{2 R_{s} q_{m 1}} .
\end{aligned}
$$

Proposition 2. Under the situation of multiperiod coordination mechanism and in the periods of one boom season and one slack season, the total expected profit of the electricity enterprise is a concave function of the ordering quantity of the thermal coal in boom and slack seasons of coal demand. Under this situation, $q_{m 1}$ and $q_{m 2}$ satisfy the following model:

$$
\begin{aligned}
\int_{\xi \lambda q_{m 1} / D_{m 1}}^{+\infty} f(x) d x & =\frac{(1+\alpha) P_{s 2}}{\left[\left(P_{m}+R_{m}-C_{m}\right) \xi\right]}, \\
\int_{\xi q_{m 2} / D_{m 2}}^{+\infty} f(x) d x & =\frac{P_{s 2}}{\left[\left(P_{m}+H_{m}-C_{m}\right) \xi\right]} .
\end{aligned}
$$

We have the proof of Proposition 2 in the Appendices.

It can be seen from formula (5) that $\lambda q_{m 1}$ is a constant. This is because the electricity enterprise knows the decisionmaking of the fulfillment rate of thermal coal by the coal enterprise, so the electricity enterprise can increase the ordering quantity of thermal coal to keep $\lambda q_{m 1}$ as a constant. In theory, the fulfillment rate of thermal coal in the boom season of coal demand has no effect on the expected profit of the electricity enterprise. But in practice, when the fulfillment rate of thermal coal is low, the initiatives of the coal enterprise to supply thermal coal are decreased and the coal enterprise may reduce the coal quality to satisfy the order. This may be an adverse effect on the electricity enterprise.

3.2.3. The Decision-Making of the Rate of Price Inflation of the Thermal Coal in the Boom Season by the Coal Enterprise. The coal enterprise makes the decisions of the rate of price inflation of the thermal coal in the boom season under the situation that $\beta$ is known. According to the assumption that the coal enterprise is rational, the coal enterprise knows the 
decision-making of the ordering quantity of the thermal coal by the electricity enterprise, that is, formula (5). The decisionmaking model is

$$
\begin{array}{ll}
\max \quad \pi_{s}^{\mathrm{DC}} & (1+\alpha) P_{s 2} \lambda q_{m 1}+P_{s 1}\left(Q_{s 1}-\lambda q_{m 1}\right) \\
& +P_{s 2}\left\{[1-\gamma \alpha-\beta(1-\lambda)] q_{m 2}+D_{o 2}\right\} \\
& -R_{s}(1-\lambda)^{2} q_{m 1} \\
& \quad-C_{s}\left\{Q_{s 1}+[1-\gamma \alpha-\beta(1-\lambda)] q_{m 2}+D_{o 2}\right\} \\
\text { s.t. } \quad & \int_{\xi \lambda q_{m 1} / D_{m 1}}^{+\infty} f(x) d x=\frac{(1+\alpha) P_{s 2}}{\left(P_{m}+R_{m}-C_{m}\right) \xi} \\
& \int_{\xi q_{m 2} / D_{m 2}}^{+\infty} f(x) d x=\frac{P_{s 2}}{\left(P_{m}+R_{m}-C_{m}\right) \xi} \\
& \lambda^{\mathrm{DC}}=1-\frac{P_{s 1}-(1+\alpha) P_{s 2}}{2 R_{s}}+\frac{\left(P_{s 2}-C_{s}\right) \beta q_{m 2}}{2 R_{s} q_{m 1}} .
\end{array}
$$

The first term in the profit function corresponds to the sales revenue of thermal coal in the boom season, the second term is the sales revenue of other coal in the boom season, the third term is the sales revenue of coal in the slack season, the fourth term is the shortage cost of thermal coal, and the fifth term is the production cost of coal.

According to formula (6), we can gain formula (7) by letting $d \pi_{s}{ }^{\mathrm{DC}} / d \alpha$ :

$$
\begin{aligned}
& \frac{2 R_{s} P_{s 2} D_{m 1}\left[\alpha^{\mathrm{DC}} P_{s 2} \lambda-R_{s}(1-\lambda)^{2}\right]}{\left(P_{m}+R_{m}-C_{m}\right) \xi^{2} f\left(\xi \lambda q_{m 1} / D_{m 1}\right)} \\
& =\left(1+\lambda^{2}\right) R_{s} P_{s 2} q_{m 1} \\
& +\lambda\left(P_{s 2}-C_{s}\right)\left(-2 \gamma R_{s}+\beta P_{s 2}\right) q_{m 2} .
\end{aligned}
$$

It can be seen from formula (7) that the rate of price inflation of the thermal coal in the boom season, $\alpha$, is a function of the coordination parameter $\gamma$.

\subsubsection{The Decision-Making of the Coordination Parameters by} the Electricity Enterprise. According to the assumption that the electricity enterprise is rational, the electricity enterprise knows the decision-making of the rate of price inflation of the thermal coal in the boom season of coal demand by the coal enterprise, that is, formula (7). Based on formula (7), the electricity enterprise makes the decisions of the coordination parameters $\beta$ and $\gamma$ as follows:

$$
\begin{aligned}
& \lambda^{\mathrm{DC}}=1-\frac{P_{s 1}-(1+\alpha) P_{s 2}}{2 R_{s}}+\frac{\left(P_{s 2}-C_{s}\right) \beta q_{m 2}}{2 R_{s} q_{m 1}}, \\
& \frac{2 R_{s} P_{s 2} D_{m 1}\left[\alpha^{\mathrm{DC}} P_{s 2} \lambda-R_{s}(1-\lambda)^{2}\right]}{\left(P_{m}+R_{m}-C_{m}\right) \xi^{2} f\left(\xi \lambda q_{m 1} / D_{m 1}\right)} \\
& =\left(1+\lambda^{2}\right) R_{s} P_{s 2} q_{m 1} \\
& \quad+\lambda\left(P_{s 2}-C_{s}\right)\left(-2 \gamma R_{s}+\beta P_{s 2}\right) q_{m 2} \\
& \quad \alpha^{\mathrm{DC}}=0, \lambda^{\mathrm{DC}}=1 .
\end{aligned}
$$

The first term is function (2), and the second term is function (7).

According to formulas (2) and (7),

$$
\begin{aligned}
& \frac{\partial \alpha^{\mathrm{DC}}}{\partial \gamma} \\
& =-\frac{\left(P_{s 2}-C_{s}\right)\left(P_{m}+R_{m}-C_{m}\right) \xi^{2} f\left(\xi \lambda q_{m 1} / D_{m 1}\right) q_{m 2}}{P_{s 2}{ }^{2} D_{m 1}} \\
& <0, \\
& \frac{\partial E \pi_{m} \text { DC }}{\partial \gamma} \\
& =-\left[\frac{(1+\alpha) P_{s 2}{ }^{2} D_{m 1}}{\left(P_{m}+R_{m}-C_{m}\right) \xi f\left(\xi \lambda q_{m 1} / D_{m 1}\right)}+P_{s 2} \lambda q_{m 1}\right] \frac{\partial \alpha}{\partial \gamma} \\
& >0 .
\end{aligned}
$$

So $\partial E \pi_{m}{ }^{\mathrm{DC}} / \partial \alpha<0$, to achieve the optimal expected profit, and $\alpha^{\mathrm{DC}}=0$ in formula (8).

According to formula (5), in theory, the fulfillment rate of thermal coal in boom seasons of coal demand has no effect on the expected profit of the electricity enterprise. But in practice, when the fulfillment rate of thermal coal is low, the initiatives of the coal enterprise to supply thermal coal are decreased and the coal enterprise may reduce the coal quality to satisfy the order. This may be an adverse effect on the electricity enterprise. The electricity enterprise should make the decision of the coordination parameter $\beta$ to increase the fulfillment rate of thermal coal in boom seasons of coal demand. So, $\lambda^{\mathrm{DC}}=1$ in formula (8).

According to formula (8), we can get Proposition 3.

Proposition 3. Under the situation of multiperiod coordination mechanism, the coordination parameters may satisfy the following models:

$$
\begin{aligned}
\beta & =\frac{\left(P_{s 1}-P_{s 2}\right) q_{m 1}}{\left(P_{s 2}-C_{s}\right) q_{m 2}}=-\frac{q_{m 1}}{q_{m 2}}+\frac{\left(P_{s 1}-C_{s}\right) q_{m 1}}{\left(P_{s 2}-C_{s}\right) q_{m 2}}, \\
\gamma & =\frac{P_{s 2}\left(2 R_{s}+P_{s 1}-P_{s 2}\right) q_{m 1}}{2 R_{s}\left(P_{s 2}-C_{s}\right) q_{m 2}} \\
& =\frac{P_{s 2}}{\left(P_{s 2}-C_{s}\right)}+\frac{P_{s 2}\left(P_{s 1}-P_{s 2}\right) q_{m 1}}{2 R_{s}\left(P_{s 2}-C_{s}\right) q_{m 2}} .
\end{aligned}
$$

According to formulas (2), (5), (7), and (10), one can gain the decision-making of the coordination parameters: the rate of price inflation of the thermal coal in the boom season, the ordering quantity of the thermal coal, and the fulfillment rate of the thermal coal in the boom season.

\section{Numerical Analysis}

Parameters of a coal-electricity supply chain in the periods of one boom season and one slack season are as follows. The price of electricity $P_{m}=4500$ (Yuan $\left./ 10^{4} \mathrm{kw}-\mathrm{h}\right)$, the 
TABLE 1: Decision and results under conditions of no coordination mechanism and multiperiod coordination mechanism.

\begin{tabular}{lcccccc}
\hline & $\alpha$ & $\lambda(\%)$ & $\gamma$ & $\beta$ & The coal enterprise & The electricity enterprise \\
\hline$U$ & 0.2 & 75 & - & - & 10815 & 10215 \\
DC & 0 & 100 & 4.30 & 1.88 & 11914 & 11758 \\
\hline
\end{tabular}

$P_{\mathrm{sp}}:$ probability of shortage of power supply.

TABLE 2: Sensitivity analysis of the decision-making of coordination parameters.

\begin{tabular}{cccccc}
\hline$\alpha$ & $\lambda(\%)$ & $\gamma$ & $\beta$ & \multicolumn{2}{c}{ Total profit in two periods } \\
The electricity enterprise
\end{tabular}

$P_{\mathrm{sp}}:$ probability of shortage of power supply.

shortage cost of electricity supply $R_{m}=300$ (Yuan $/ 10^{4} \mathrm{kw}-\mathrm{h}$ ), the generating $\operatorname{cost} C_{m}=1000$ (Yuan $/ 10^{4} \mathrm{kw}-\mathrm{h}$ ), the generating quantity per unit coal $\xi=0.33\left(10^{4} \mathrm{kw}-\mathrm{h} / \mathrm{ton}\right)$, and the production cost of coal $C_{s}=300$ (Yuan/ton). In boom seasons of coal demand, the expected demand of electricity $D_{m 1}=50000\left(10^{4} \mathrm{kw}-\mathrm{h}\right)$, the order quantity of other coal $D_{o 1}=150000$ (tons), the output capacity of coal $Q_{s 1}=$ 250000 (tons), the market price of coal $P_{s 1}=800$ (Yuan/ton), the coefficient of shortage cost $R_{s}=400$, and the rate of price inflation of the thermal coal in boom seasons $\alpha_{0}=0.2$. In slack seasons of coal demand, the demand of electricity $D_{m 2}=40000\left(10^{4} \mathrm{kw}-\mathrm{h}\right)$, the order quantity of other coal $D_{o 2}=80000$ (tons), the output capacity of coal $Q_{s 2}=250000$ (tons), and the market price of coal $P_{s 2}=$ 500 (Yuan/ton). $X$ is subject to uniform distribution $U(1-$ $n, 1+n)$, where $n=0.15$.

The decision-making results are shown in Table 1. From Table 1, it can be seen that, under the conditions of double price regulations, when the rate of price inflation of the thermal coal in the boom seasons is $20 \%$, the fulfillment rate of the thermal coal in the boom seasons is only $75 \%$, and the probability of shortage proportion of price element of electricity supply in boom seasons is $8 \%$.
Under the conditions of multiperiod coordination mechanism, the rate of price inflation of the thermal coal in the boom seasons decreases to 0 , and the fulfillment rate of the thermal coal in the boom seasons increases to $100 \%$; meanwhile the probability of shortage proportion of price element of electricity supply in boom seasons decreases to 0 . Furthermore, the expected profits of the coal enterprise and the electricity enterprise both rise under the conditions of multiperiod coordination mechanism.

The sensitivity analysis of the decision-making of coordination parameters is shown in Table 2. It can be seen from Table 2 that the total profits of the coal enterprise and the electricity enterprise in two periods achieve the maximal value when $\gamma=4.30$ and $\beta=1.88$.

\section{Discussions and Conclusions}

Based on the mechanism of coal-electricity price conflict under conditions of double price regulations [47], we study the multiperiod coordination mechanism in coal-electricity supply chain. The study reveals that, in order to solve the conflict between coal and electricity, the transverse price 
double track caused by coal price regulation and the longitudinal price double track caused by electricity price regulation should be eased. The advice of coal-electricity integration [48] cannot solve the problem of the longitudinal price double track. And coal-electricity integration is not easy to carry out widely. The linkage mechanism for the coal-electricity price [49] may not solve the problem of the transverse price double track. Also the electricity price increase has an adverse influence on the total output, Gross Domestic Product (GDP), and the Consumer Price Index (CPI) [50]. The mechanism of peak shaving reserve of thermal coal may increase the enthusiasm of the power enterprises to order more thermal coal and the initiatives of the coal enterprises to supply more thermal coal [47]. However, the construction of peak shaving reserve warehouses of thermal coal would not be easy.

In boom seasons of coal demand, the multiperiod coordination mechanism may not only reduce the price of thermal coal but also increase the fulfillment rate of thermal coal. Meanwhile, the ordering quantity of thermal coal is increased and the shortage probability of electricity supply is decreased. Thereby, the multiperiod coordination mechanism may ease the conflicts between coal and electricity. Thus, it is an effective mechanism to solve the conflict problem of coalelectricity in China.

The insights of the analysis and findings of the paper are as follows. Under the situation of multiperiod coordination mechanism, the reasonable decision of the dynamic coordinate parameters of the fulfillment rate and the price by electricity firms can guide the coal firms to reduce the price of thermal coal, increase the fulfillment rate of thermal coal, and stabilize the coal sales in slack seasons. The multiperiod coordination mechanism can ease the transverse price double track caused by coal price regulation and the longitudinal price double track caused by electricity price regulation. Especially under the circumstance of lifting the control of the price of the thermal coal step by step, the conflict between coal and electricity during the boom season of coal demand will inevitably become more intense. Against this background, it is an effective way to alleviate the conflict by establishing multiperiod coordination mechanism of coal firms and electricity firms.

\section{Appendices}

\section{A. Proof of Proposition 1}

Since

$$
\begin{aligned}
\frac{d \pi_{s}^{\mathrm{DC}}}{d \lambda}= & (1+\alpha) P_{s 2} q_{m 1}-P_{s 1} q_{m 1}+2 R_{s}(1-\lambda) q_{m 1} \\
& +\left(P_{s 2}-C_{s}\right) \beta q_{m 2}, \\
\frac{d^{2} \pi_{s}^{\mathrm{DC}}}{d \lambda^{2}}= & -2 R_{s} q_{m 1}<0,
\end{aligned}
$$

so $\pi_{s}{ }^{\mathrm{DC}}$ is a concave function of $\lambda$, and formula (2) is gained if $d \pi_{s}{ }^{\mathrm{DC}} / d \lambda=0$.

\section{B. Proof of Proposition 2}

Since

$$
\begin{aligned}
& \frac{\partial E \pi_{m}{ }^{\mathrm{DC}}}{\partial q_{m 1}}=\left[\left(P_{m}+R_{m}-C_{m}\right) \xi \int_{\xi \lambda q_{m 1} / D_{m 1}}^{+\infty} f(x) d x\right. \\
& \left.-(1+\alpha) P_{s 2}\right]\left[1-\frac{P_{s 1}-(1+\alpha) P_{s 2}}{2 R_{s}}\right], \\
& \frac{\partial E \pi_{m}{ }^{\mathrm{DC}}}{\partial q_{m 2}}=\frac{\left(P_{m}+R_{m}-C_{m}\right) \xi\left(P_{s 2}-C_{s}\right) \beta}{2 R_{s}} \\
& \cdot \int_{\xi \lambda q_{m 1} / D_{m 1}}^{+\infty} f(x) d x+\left(P_{m}+R_{m}-C_{m}\right) \\
& \xi \int_{\xi q_{m 2} / D_{m 2}}^{+\infty} f(x) d x-\frac{\beta\left(P_{s 2}-C_{s}\right)(1+\alpha) P_{s 2}}{2 R_{s}} \\
& -P_{s 2} \text {, } \\
& \frac{\partial^{2} E \pi_{m}{ }^{\mathrm{DC}}}{\partial q_{m 1}{ }^{2}}=-\left(P_{m}+R_{m}-C_{m}\right) \frac{\xi^{2} \lambda}{D_{m 1}} f\left(\frac{\xi \lambda q_{m 1}}{D_{m 1}}\right)[1 \\
& \left.-\frac{P_{s 1}-(1+\alpha) P_{s 2}}{2 R_{s}}\right] \leq 0, \\
& \frac{\partial^{2} E \pi_{m}{ }^{\mathrm{DC}}}{\partial q_{m 2}{ }^{2}}=-\frac{\left(P_{m}+R_{m}-C_{m}\right) \xi^{2}}{D_{m 2}} f\left(\frac{\xi q_{m 2}}{D_{m 2}}\right) \leq 0 ; \\
& \frac{\partial^{2} E \pi_{m}{ }^{\mathrm{DC}}}{\partial q_{m 1} \partial q_{m 2}}=0 \\
& \frac{\partial^{2} E \pi_{m}{ }^{\mathrm{DC}}}{\partial q_{m 2} \partial q_{m 1}}=-\frac{\left(P_{m}+R_{m}-C_{m}\right) \xi^{2} \lambda\left(P_{s 2}-C_{s}\right) \beta}{2 R_{s} D_{m 1}} \\
& \cdot f\left(\frac{\xi \lambda q_{m 1}}{D_{m 1}}\right) \text {. }
\end{aligned}
$$

So, the Hessen matrix $\left[\begin{array}{cc}\partial^{2} E \pi_{m}{ }^{\mathrm{DC}} / \partial q_{m 1}{ }^{2} & \partial^{2} E \pi_{m}{ }^{\mathrm{DC}} / \partial q_{m 1} \partial q_{m 2} \\ \partial^{2} E \pi_{m}{ }^{\mathrm{DC}} / \partial q_{m 2} \partial q_{m 1} & \partial^{2} E \pi_{m}{ }^{\mathrm{DC}} / \partial q_{m 2}{ }^{2}\end{array}\right]$ is a negative matrix. Therefore, $E \pi_{m}{ }^{\mathrm{DC}}$ is a concave function of $q_{m 1}$ and $q_{m 2}$, and formula (8) is gained if $\partial E \pi_{m}{ }^{\mathrm{DC}} / \partial q_{m 1}=0$ and $\partial E \pi_{m}{ }^{\mathrm{DC}} / \partial q_{m 2}=0$.

\section{Conflict of Interests}

The authors declare that there is no conflict of interests regarding the publication of this paper.

\section{Acknowledgments}

This research was supported by the National Natural Science Foundation of China (Grant no. 71201164), China Postdoctoral Science Foundation (Grant no. 2014M561658), and Philosophy and Social Science Research in Colleges and Universities in Jiangsu Province (Grant no. 2014SJB050). 


\section{References}

[1] L. Shen, T.-M. Gao, and X. Cheng, "China's coal policy since 1979: a brief overview," Energy Policy, vol. 40, no. 1, pp. 274-281, 2012.

[2] P. Arocena, I. Contín, and E. Huerta, "Price regulation in the Spanish energy sectors: who benefits?" Energy Policy, vol. 30, no. 10, pp. 885-895, 2002.

[3] I. Matsukawa, "The effects of average revenue regulation on electricity transmission investment and pricing," Energy Economics, vol. 30, no. 3, pp. 696-714, 2008.

[4] T. A. Johnsen and O. J. Olsen, "Regulated and unregulated Nordic retail prices," Energy Policy, vol. 39, no. 6, pp. 3337-3345, 2011.

[5] A. Ciarreta and M. P. Espinosa, "The impact of regulation on pricing behavior in the Spanish electricity market (2002-2005)," Energy Economics, vol. 34, no. 6, pp. 2039-2045, 2012.

[6] G. Coco and C. De Vincenti, "Can price regulation increase cost-efficiency?” Research in Economics, vol. 58, no. 4, pp. 303317, 2004.

[7] D. L. Weisman, "Is there 'Hope' for price cap regulation?" Information Economics and Policy, vol. 14, no. 3, pp. 349-370, 2002.

[8] D. L. Weisman, "Price regulation and quality," Information Economics and Policy, vol. 17, no. 2, pp. 165-174, 2005.

[9] M. Breton and M. Kharbach, "Transportation and storage under a dynamic price cap regulation process," Energy Economics, vol. 34, no. 4, pp. 918-929, 2012.

[10] G. Guthrie, "Regulated prices and real options," Telecommunications Policy, vol. 36, no. 8, pp. 650-663, 2012.

[11] L. Evans and G. Guthrie, "Price-cap regulation and the scale and timing of investment," RAND Journal of Economics, vol. 43, no. 3, pp. 537-561, 2012.

[12] D. A. Galbi, "Regulating prices for shifting between service providers," Information Economics and Policy, vol. 13, no. 4, pp. 393-410, 2001.

[13] I. Dumitru and I. Jianu, "The Balassa-Samuelson effect in Romania-the role of regulated prices," European Journal of Operational Research, vol. 194, no. 3, pp. 873-887, 2009.

[14] Z.-X. Wang, "Application of grey linear control theory for price regulation in China's real estate market," Kybernetes, vol. 42, no. 3, pp. 413-422, 2013.

[15] D. E. M. Sappington and D. L. Weisman, "Revenue sharing in incentive regulation plans," Information Economics and Policy, vol. 8, no. 3, pp. 229-248, 1996.

[16] E. Iossa and F. Stroffolini, "Price cap regulation, revenue sharing and information acquisition," Information Economics and Policy, vol. 17, no. 2, pp. 217-230, 2005.

[17] T.-P. Hsieh and C.-Y. Dye, "A production-inventory model incorporating the effect of preservation technology investment when demand is fluctuating with time," Journal of Computational and Applied Mathematics, vol. 239, pp. 25-36, 2013.

[18] K. Kogan and A. Herbon, "Production under periodic demand update prior to a single selling season: a decomposition approach," European Journal of Operational Research, vol. 184, no. 1, pp. 133-146, 2008.

[19] M.-S. Chern, H.-L. Yang, J.-T. Teng, and S. Papachristos, "Partial backlogging inventory lot-size models for deteriorating items with fluctuating demand under inflation," European Journal of Operational Research, vol. 191, no. 1, pp. 127-141, 2008.
[20] I. Moon, B. C. Giri, and B. Ko, "Economic order quantity models for ameliorating/deteriorating items under inflation and time discounting," European Journal of Operational Research, vol.162, no. 3, pp. 773-785, 2005.

[21] H.-L. Yang, J.-T. Teng, and M.-S. Chern, "Deterministic inventory lot-size models under inflation with shortages and deterioration for fluctuating demand," Naval Research Logistics, vol. 48, no. 2, pp. 144-158, 2001.

[22] K. Skouri and S. Papachristos, "Note on 'deterministic inventory lot-size models under inflation with shortages and deterioration for fluctuating demand' by Yang et al," Naval Research Logistics, vol. 49, no. 5, pp. 527-529, 2002.

[23] L. Yang, C. T. Ng, and T. C. E. Cheng, "Optimal production strategy under demand fluctuations: technology versus capacity," European Journal of Operational Research, vol. 214, no. 2, pp. 393-402, 2011.

[24] C.-Y. Dye and T.-P. Hsieh, "Deterministic ordering policy with price- and stock-dependent demand under fluctuating cost and limited capacity," Expert Systems with Applications, vol. 38, no. 12, pp. 14976-14983, 2011.

[25] C.-Y. Dye and T.-P. Hsieh, "A particle swarm optimization for solving lot-sizing problem with fluctuating demand and preservation technology cost under trade credit," Journal of Global Optimization, vol. 55, no. 3, pp. 655-679, 2013.

[26] F. Y. Chen, Y. Feng, and D. Simchi-Levi, "Uniform distribution of inventory positions in two-echelon periodic review systems with batch-ordering policies and interdependent demands," European Journal of Operational Research, vol. 140, no. 3, pp. 648-654, 2002.

[27] S. Banerjee and A. Sharma, "Inventory model for seasonal demand with option to change the market," Computers \& Industrial Engineering, vol. 59, no. 4, pp. 807-818, 2010.

[28] P. S. You, "Optimal replenishment policy for product with season pattern demand," Operations Research Letters, vol. 33, no. 1, pp. 90-96, 2005.

[29] S. Panda, S. Senapati, and M. Basu, "Optimal replenishment policy for perishable seasonal products in a season with ramp-type time dependent demand," Computers \& Industrial Engineering, vol. 54, no. 2, pp. 301-314, 2008.

[30] Y.-R. Chen and C.-Y. Dye, "Application of particle swarm optimisation for solving deteriorating inventory model with fluctuating demand and controllable deterioration rate," International Journal of Systems Science. Principles and Applications of Systems and Integration, vol. 44, no. 6, pp. 1026-1039, 2013.

[31] C.-I. Hsu and H.-C. Li, "Reliability evaluation and adjustment of supply chain network design with demand fluctuations," International Journal of Production Economics, vol. 132, no. 1, pp. 131-145, 2011

[32] C.-T. Chang and H.-C. Chou, "A coordination system for seasonal demand problems in the supply chain," Applied Mathematical Modelling, vol. 37, no. 6, pp. 3674-3686, 2013.

[33] C.-Y. Dye and L.-Y. Ouyang, "A particle swarm optimization for solving joint pricing and lot-sizing problem with fluctuating demand and trade credit financing," Computers \& Industrial Engineering, vol. 60, no. 1, pp. 127-137, 2011.

[34] D. W. Cho and Y. H. Lee, "The value of information sharing in a supply chain with a seasonal demand process," Computers \& Industrial Engineering, vol. 65, no. 1, pp. 97-108, 2013.

[35] Y. Wu and D. Z. Zhang, "Demand fluctuation and chaotic behaviour by interaction between customers and suppliers," International Journal of Production Economics, vol. 107, no. 1, pp. 250-259, 2007. 
[36] J. Chen and L. Xu, "Coordination of the supply chain of seasonal products," IEEE Transactions on Systems, Man and Cybernetics Part A: Systems and Humans, vol. 31, no. 6, pp. 524-532, 2001.

[37] K. Chen and T. Xiao, "Ordering policy and coordination of a supply chain with two-period demand uncertainty," European Journal of Operational Research, vol. 215, no. 2, pp. 347-357, 2011.

[38] Y. Liu, F. Qin, M. J. Fry, and A. S. Raturi, "Multi-period modeling of two-way price commitment under price-dependent demand," European Journal of Operational Research, vol. 221, no. 3, pp. 546-556, 2012.

[39] Y. Aviv and A. Federgruen, "Capacitated multi-item inventory systems with random and seasonally fluctuating demands: implications for postponement strategies," Management Science, vol. 47, no. 4, pp. 512-531, 2001.

[40] P. K. Kopalle, A. G. Rao, and J. L. Assunção, "Asymmetric reference price effects and dynamic pricing policies," Marketing Science, vol. 15, no. 1, pp. 60-85, 1996.

[41] G. Fibich, A. Gavious, and O. Lowengart, "Explicit solutions of optimization models and differential games with nonsmooth (asymmetric) reference-price effects," Operations Research, vol. 51, no. 5, pp. 721-734, 2003.

[42] I. Popescu and Y. Wu, "Dynamic pricing strategies with reference effects," Operations Research, vol. 55, no. 3, pp. 413-429, 2007.

[43] D. Besanko and W. L. Winston, "Optimal price skimming by a monopolist facing rational consumers," Management Science, vol. 36, no. 5, pp. 555-567, 1990.

[44] J. Conlisk, E. Gerstner, and J. Sobel, "Cyclic pricing by a durable goods monopolist," The Quarterly Journal of Economics, vol. 99, no. 3, pp. 489-505, 1984.

[45] J. Sobel, "Durable goods monopoly with entry of new consumers," Econometrica, vol. 59, no. 5, pp. 1455-1485, 1991.

[46] H.-s. Ahn, M. Gümüs, and P. Kaminsky, "Pricing and manufacturing decisions when demand is a function of prices in multiple periods," Operations Research, vol. 55, no. 6, pp. 1039-1057, 2007.

[47] H. Peng, M. Zhou, and F. Wang, "Research on double price regulations and peak shaving reserve mechanism in coalelectricity supply chain," Mathematical Problems in Engineering, vol. 2013, Article ID 542041, 12 pages, 2013.

[48] X. Zhao, T. P. Lyon, F. Wang, and C. Song, "Why do electricity utilities cooperate with coal suppliers? A theoretical and empirical analysis from China," Energy Policy, vol. 46, pp. 520-529, 2012.

[49] J.-L. Jiao, H.-Z. Ge, and Y.-M. Wei, "Impact analysis of China's coal-electricity price linkage mechanism: results from a game model," Journal of Policy Modeling, vol. 32, no. 4, pp. 574-588, 2010.

[50] Y. X. He, S. L. Zhang, L. Y. Yang, Y. J. Wang, and J. Wang, "Economic analysis of coal price-electricity price adjustment in China based on the CGE model," Energy Policy, vol. 38, no. 11, pp. 6629-6637, 2010. 


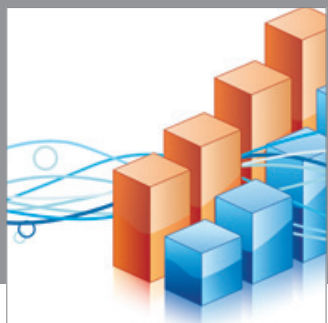

Advances in

Operations Research

mansans

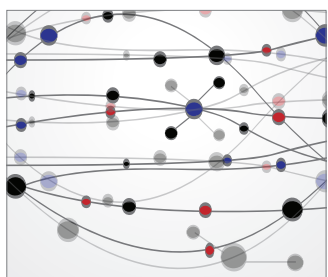

The Scientific World Journal
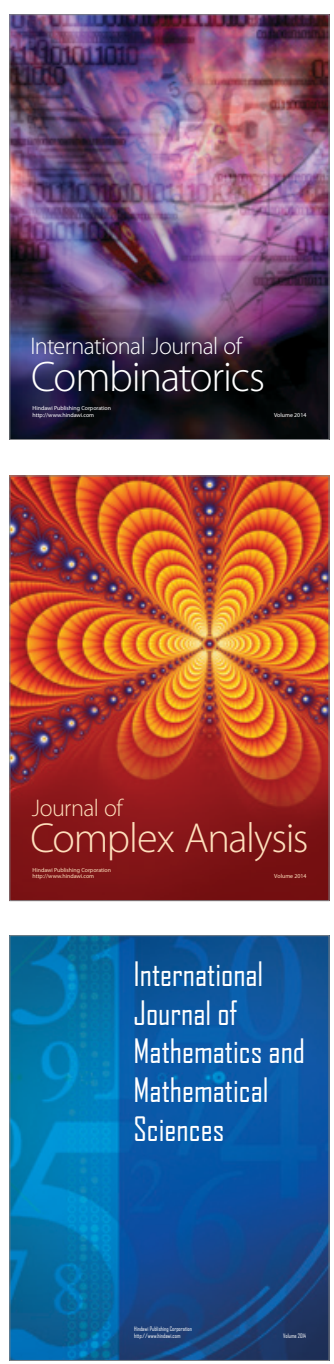
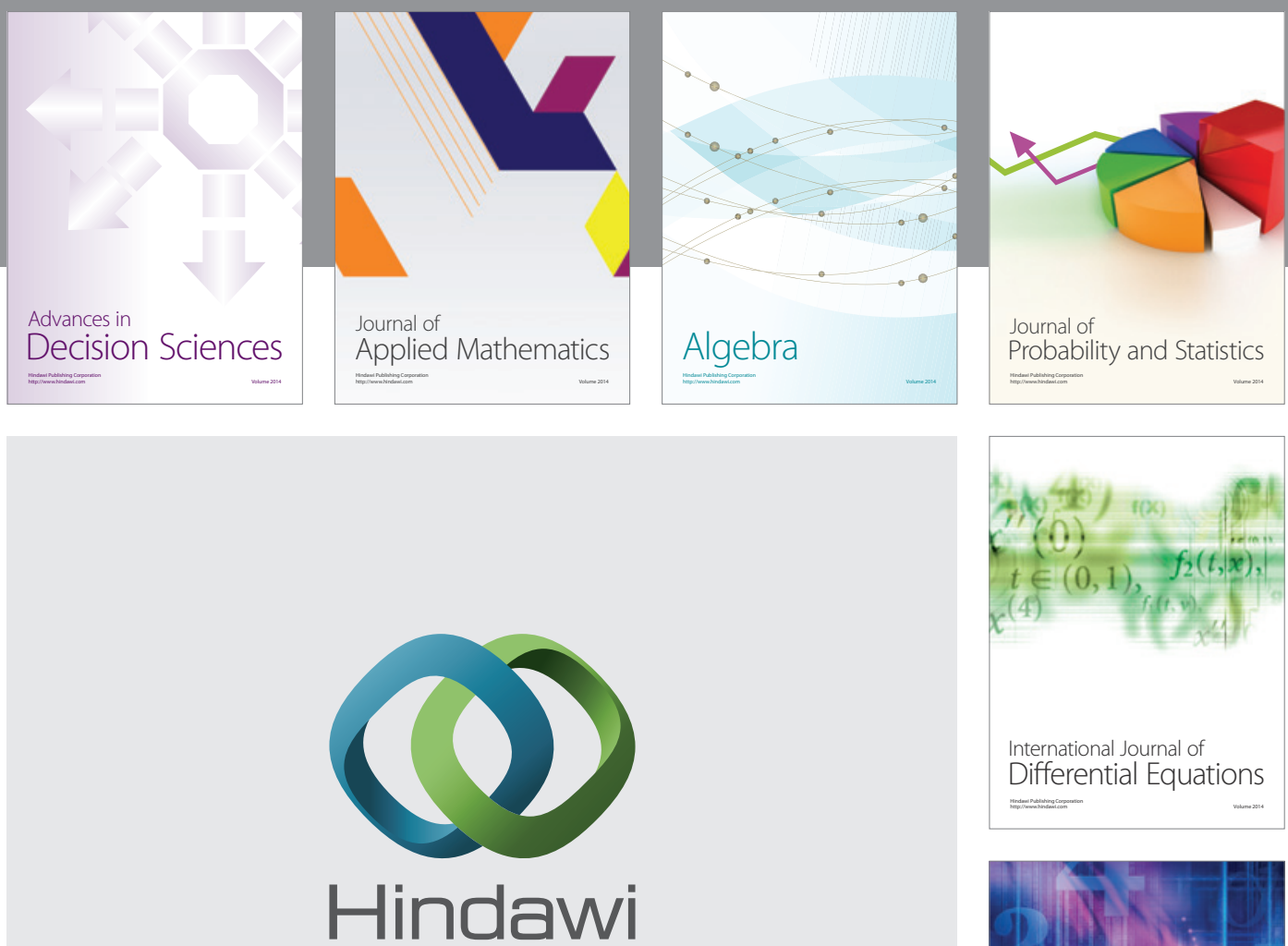

Submit your manuscripts at http://www.hindawi.com
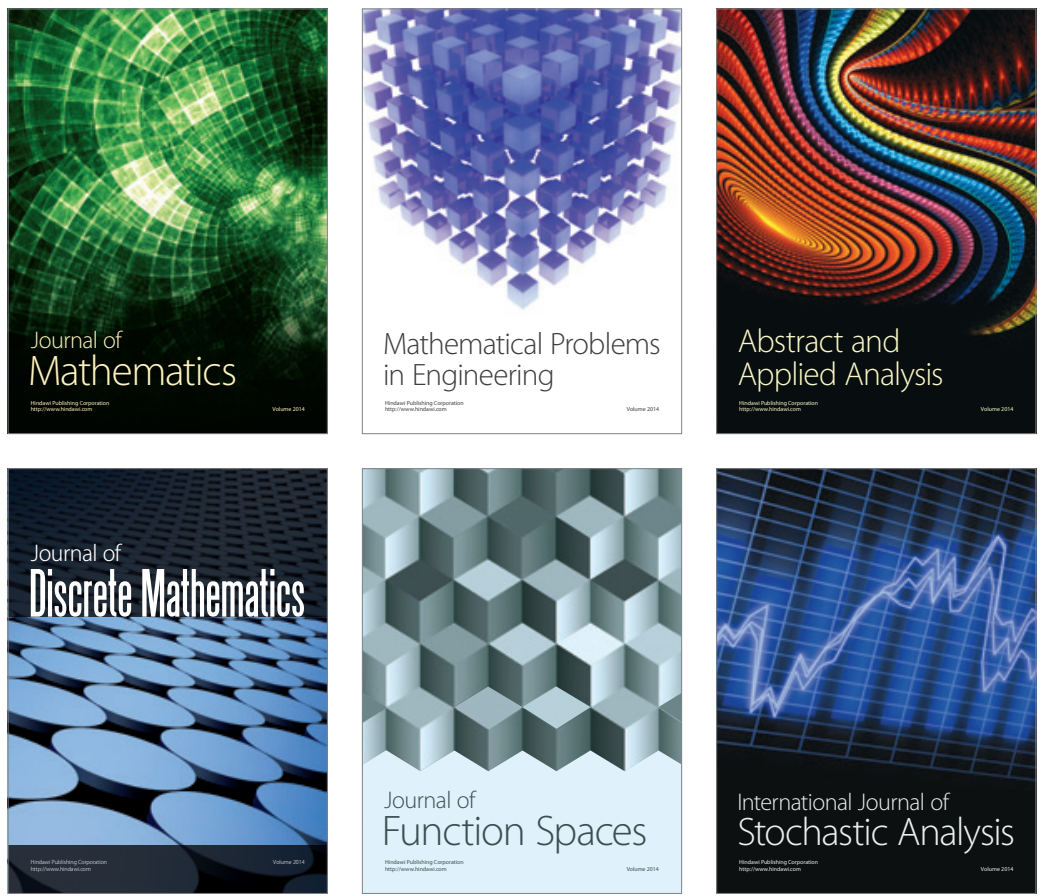

Journal of

Function Spaces

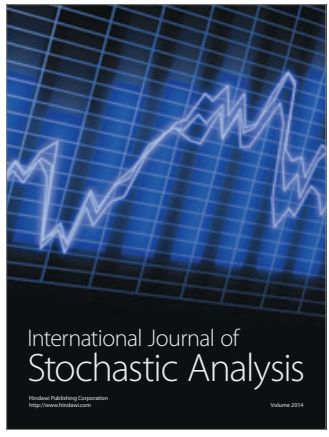

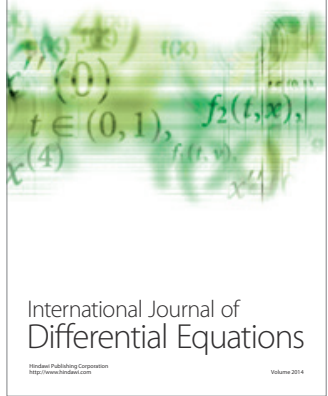
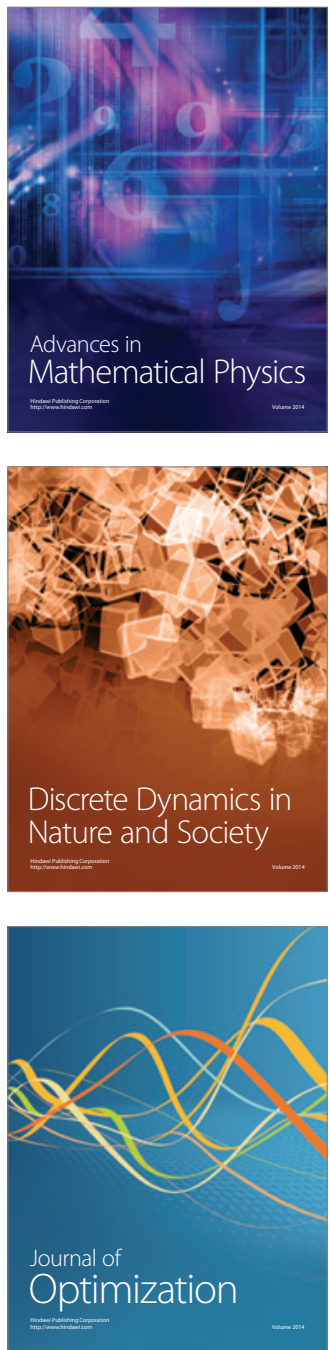